\title{
ANALYSIS ON TRENDING ELECTROMAGNETIC EXPOSURE LEVELS AT HOMES AND PROXIMITY NEXT TO BASE STATIONS ALONG THREE YEARS IN A CITY
}

\author{
Osman ÇEREZCİ, Baha KANBEROĞLU, Şuayb Çağrı YENER \\ Department of Electric-Electronic Engineering, Faculty of Engineering, Sakarya University, Esentepe Campus, \\ 54055, Serdivan, Sakarya, Turkey
}

Submitted 18 Nov. 2013; accepted 07 Jul. 2014

\begin{abstract}
Electromagnetic field exposure levels of people living in the closest houses to the GSM transmitting antennas were investigated in a city between 2010 and 2012. At the end of 3-year period, trend of the electromagnetic exposure levels was determined especially for indoor/outdoor environments near the base station antennas. Because of increasing number of base stations by years and changing of the technology, it is determined that average electromagnetic exposure values in the city increased in a certain extent each year. Total and frequency selective measurements were performed in indoor/outdoor places. The results were compared by International ICNIRP limits. In addition, possibility of the compliance with some European countries which have applied low limit values are discussed to minimize involuntary exposure to electromagnetic fields at indoor/outdoor environments. Consequently, a suggestion is made and discussed for obtaining relatively homogeneous distribution of electromagnetic field exposure at indoor/ outdoor environments near base station antennas to eliminate extent values.
\end{abstract}

Keywords: electromagnetic field exposure, base station, indoor environment, measurement.

\section{Introduction}

In recent years, with continuous development of mobile communication, electromagnetic exposure from GSM base station antennas has changed due to the increasing number of base stations placed in close of residential areas, schools and streets. In order to control and limit the electromagnetic field exposure levels of people, international guidelines and standards were established (ICNIRP 1998; EN 50413: 2008). Also, national regulations based on these guidelines and standards are prepared and taken into account (BTK 2011; Karpowicz et al. 2006; FOEN 1999). A number of researchers studied on public and occupational exposure from base station antennas with performing field measurements (Baltrenas et al. 2012; Wu et al. 2012; Alanko et al. 2008). Meanwhile, theoretical analysis of electromagnetic exposure levels has been also studied.

The level of human exposure to electromagnetic radiation from base station antennas can be calculated theoretically (Poljak et al. 2004). A numerical and experimental analysis has been performed with human exposure in close of the base station antenna via phantom model (Gosselin et al. 2009). With reflecting walls and buildings, human exposure studies are expanded to a urban environment model (Bernardi et al. 2000). Existence of an exclusion zone is important to keep people away from excessive exposure in the vicinity of base station antennas (Singh 2012). The electric fields radiated from base station antennas are evaluated and compared with the measurements and permissible exposure limits to determine the safety zone for electromagnetic exposure of base station antenna (Chen et al. 2009). On the other hand, another way to determine safety distance for electromagnetic exposure is to calculate Specific Absorption Rate (SAR) and compare with basic restrictions (Joseph, Martens 2005). By means of SAR calculations, minimum safety distance is to be calculated for a person in the near field of a base station for single frequency (Cooper et al. 2002). The actual situation is highlighted via measuring the GSM frequency-based electromagnetic environment parameters as electric field, magnetic field or electromagnetic power density which are spread to the house and street of the cities (Wu et al. 2012). Also, measurements are necessary to compare them

Corresponding author: Osman Çerezci

E-mail: cerezci@sakarya.edu.tr 
with standards to verify whether the electromagnetic exposure levels are appropriate for limits (Neskovic et al. 2011). Electromagnetic field distribution measurements can be used to determine compliance with exposure limits (Higashiyama, Tarusawa 2011). The number and distribution of base stations are more densely in populated areas than in non-populated areas (Viel et al. 2009). Base stations operating in densely populated cities in GSM 900, 1800 and $2100 \mathrm{MHz}$ frequency bands are continuously evolving due to the conditions of competition and the need of better response to increasing customer demands. This evolution is carried out by replacing base antennas with new high-gain antennas or establishing a new base station in the targeted area. Naturally, electromagnetic field density of environment has also changed in parallel to this evolution process. Because of changing process, people living near base stations, especially in indoor places, may be exposed to several times more electromagnetic field than those living farther away from base stations. Excessive exposure of people to electromagnetic fields can be avoided by positioning the base antennas appropriately (Alanko et al. 2008).

Intensity of electromagnetic radiation emitted from base station antennas changes according to parameters such as being in the main lobe of antenna, distance from the antenna and exposure duration (Baltrenas et al. 2012). Unnoticed continuous exposure situation occurs for a human being who lives against or near the base station antennas or spends a considerable time there. Therefore, monitoring the trend of increasing electromagnetic field in GSM frequencies by performing control measurements at indoor places in parallel with the evolution of base stations in cities are important to determine the involuntary exposure to electromagnetic radiation. Information derived from these studies is used to control the levels and estimate the future values of electromagnetic radiation in cities and specify the minimum electromagnetic exposure possibility (Çerezci, Şeker 2010).

In this study, GSM frequency-based electromagnetic radiation was measured especially in living areas closest to the base antennas and change of electromagnetic exposure over the years investigated during a 3-year period starting from 2010. Measurements were performed in Turkey's fourth largest metropolis Bursa's 300000-populated Nilüfer district. 86 and 98 measurements were performed at indoor locations in 2010 and 2011, respectively. In 2012, with increasing number of base stations, 228 GSM frequency-based electromagnetic radiation measurements were done at indoor and outdoor locations. 61 measurements were performed at outdoor locations like bus stops and frequently used, crowded points in front of the main lobe of base station antenna that are mounted on the street lighting poles. Briefly, during 3-year period, 412 measurements were performed at 250 locations (189 indoor and 61 outdoor) in the distance 15-40 meters from the base stations. 64 of 250 locations investigated over 3 years (2010 to 2012), 34 investigated twice(2010-2011 or 2011-2012) and 152 investigated only one time (14 in 2010 and 138 in 2012).

The measurement results were compared with ICNIRP and national exposure limits. Also, the increase trends in graphics were interpreted by years. The aim of the regulations of EMF's are to protect people from discomforting effects. Therefore, maximum potential fields need to be determined at so called "sensitive areas" in principle rooms which are used by people regularly for continuous periods.

This study is an updated version of previous studies (Baltrenas et al. 2012; Bernardi et al. 2000; Viel et al. 2009; $\mathrm{Wu}$ et al. 2012) that had been published. The measurement period and the continuity of the study are the main differences. This study showed continuation and measurements were repeated in same places every coming year from 2010. Meanwhile, Nilüfer municipality had announced the results of the measurements as an annual report to increase public awareness on this subject and help people to monitor electromagnetic exposure level in Nilüfer city. During 3-year period, with repeated and continuous measurements, involuntary exposure to electromagnetic fields at indoor/outdoor environments, especially at sensitive areas, was controlled and analyzed. These measurements are helpful to obtain relatively homogeneous distribution of electromagnetic field exposure at indoor/outdoor environments near base station antennas and to minimize the exposure to electromagnetic fields. Also, the presented measurement data, in this study, is expected to reflect the general pattern of electromagnetic exposure level in the distance 15-40 meters from standardized base station antennas in Turkey and also in other countries because of the use of similar infrastructure worldwide. But detailed analysis of electromagnetic exposure in particular locations needs individual assessment, because of the significant variations of exposure level between particular locations presented in this study.

\section{Electromagnetic safety regulations}

Safety requirements for limiting exposure to time varying electric and magnetic fields are enforced by regulations. At international level, safety guidelines for electromagnetic exposure of workers/general public and controlled/uncontrolled environments have been issued by the International Commission on Non-Ionizing Radiation Protection (ICNIRP 1998), American National Standards Institute (ANSI) and Federal Communication Commission (FCC) and some of the other regularly boards.

The ICNIRP guidance's for EMF exposure which GSM base stations must satisfy changes between $41 \mathrm{~V} / \mathrm{m}$ 
and $61 \mathrm{~V} / \mathrm{m}$ depending on the operating frequency. Some countries such as Switzerland, Italy and Poland have applied lower limits in sensitive areas from ICNIRP levels. The limits for the total EMF's from GSM base station antennas are $5 \mathrm{~V} / \mathrm{m}$ in Switzerland and $7 \mathrm{~V} / \mathrm{m}$ for Poland. The regulations for GSM frequency range have been generated with reference to the ICNIRP regulations by BTK (Information and Communication Technologies Authority) in Turkey. Total GSM exposure limits generated by BTK are equal to ICNIRP reference levels.

Maximum permissible exposure limits for single GSM and total environment at GSM frequencies presented in BTK guidelines are given in Table 1 and 2 . Single GSM exposure limit for electric field is $1 / 4$ of total GSM exposure limit of BTK and ICNIRP reference level. Also, single GSM exposure limit for power density is $1 / 16$ of total GSM exposure limit as given in Table 2.

Due to the signals emitted from base station antennas at different frequencies, the electromagnetic field exposure study was focused on measuring the total of all GSM frequencies at any point of the city.

A comparison table among the reference level of Turkey, Switzerland, Italy and Poland are given in Table 3. As

Table 1. Maximum permissible exposure limits at GSM frequencies presented in BTK guidelines (electric field)

\begin{tabular}{ccc}
\hline Frequency & $\begin{array}{c}\text { GSM Band Electric } \\
\text { Field Strength (V/m) } \\
\text { (Single GSM) }\end{array}$ & $\begin{array}{c}\text { GSM Band Electric } \\
\text { Field Strength (V/m) } \\
\text { (Total GSM) }\end{array}$ \\
\hline $900 \mathrm{MHz}$ & 10.23 & 41.25 \\
$1800 \mathrm{MHz}$ & 14.47 & 58.34 \\
$2100 \mathrm{MHz}$ & 15 & 61 \\
\hline
\end{tabular}

Table 2. Maximum permissible exposure limits at GSM frequencies presented in BTK guidelines (power density)

\begin{tabular}{ccc}
\hline Frequency & $\begin{array}{c}\text { GSM Band Power } \\
\text { Density }\left(W / \mathrm{m}^{2}\right) \\
(\text { Single GSM) }\end{array}$ & $\begin{array}{c}\text { GSM Band Power } \\
\text { Density }\left(\mathrm{W} / \mathrm{m}^{2}\right) \\
\text { (Total GSM) }\end{array}$ \\
\hline $900 \mathrm{MHz}$ & 0.28 & 4.5 \\
$1800 \mathrm{MHz}$ & 0.56 & 9 \\
$2100 \mathrm{MHz}$ & 0.66 & 10.5 \\
\hline
\end{tabular}

Table 3. Maximum permissible total exposure limits of Turkey, Italy, Switzerland and Poland at GSM frequencies

\begin{tabular}{lcc}
\hline $\begin{array}{c}\text { Country } \\
\text { (Total Environment) }\end{array}$ & $\begin{array}{c}\text { GSM Band } \\
\text { Electric Field } \\
\text { Strength }(\mathrm{V} / \mathrm{m})\end{array}$ & $\begin{array}{c}\text { GSM Band Power } \\
\text { Density }\left(\mathrm{W} / \mathrm{m}^{2}\right)\end{array}$ \\
\hline Turkey & $41-61$ & $4.5-10.5$ \\
Italy & 6 & 0.1 \\
Switzerland & 5 & $0.042-0.095$ \\
Poland & 7 & 0.1 \\
\hline
\end{tabular}

it can be seen from the table that the total limit levels of Turkey for electric field is seven-eight times greater than other countries and at least 50 times greater for power density.

\section{Measurement and method}

In this study, with the partnership of Bursa-Nilüfer municipality public health department and Sakarya University, 412 electromagnetic field measurements were performed at sensitive places of residents and streets near base stations between 2010 and 2012. At the first step of the project, houses to be measured were decided at the locations where active base station existed. The choice of locations was made in cooperation with Bursa-Nilüfer municipality public health department. The parameters as whether the location of measurement point was in front of the main lobe of the base antenna or not and distance to the base antenna used for evaluation of the measurement results were taken into account during the decision process. Then, permissions required for the measurement program were taken from the people living in the houses. During 3 -year period, the decision and permission steps repeated at the beginning of every year.

In 2010 and 2011, base stations in Nilüfer district were located on the roof of the buildings. Due to this situation, measurements were performed in the rooms of houses at the upper floor of the neighbour buildings to determine the total maximum exposure. In 2012, it was noticed that in addition to the base station antennas placed on the roof of the buildings, new base stations antennas were mounted on the street lighting poles at a height of 4-5 meters located through the street. The base stations on the lighting poles were located frequently on the streets and the number of base stations increased by $25 \%$ in the city due to this application. Finally, the measurements in the last year were performed at locations such as bus stops located in front of base antennas or on the way of people used for going to their homes and works where base station antennas were placed on lighting poles. Street measurements that consist can give an idea about determining the electromagnetic field levels at people's walking and transition areas placed opposite to the increasing base station placement application on low altitude street lighting poles.

All spot and continuous measurements were done at far field of base antennas by using PMM 8053 broadband field meter with EP33M isotropic E-field Probe $700 \mathrm{MHz}-3 \mathrm{GHz}$, Narda NBM 550 broadband field meter with EF0691 isotropic E-field Probe and Narda SRM 3006 Selective radiation meter with $27 \mathrm{MHz}-3 \mathrm{GHz}$ isotropic E-field Probe. The broadband field meter measures instantaneous field strength of all signals presented in a large frequency band. Therefore, broadband field 
meter cannot distinguish between signals coming from different transmitting sites. This does not expose a great problem when measuring field levels are in regard to limits recommended by ICNIRP regulations which range up to $61 \mathrm{~V} / \mathrm{m}$. Electric field values at other frequency bands except GSM frequency were found to be lower than $0.01 \mathrm{~V} / \mathrm{m}$ via using spectrum analyzer at the measurement points. Thus, signal level outside GSM frequency bands was recognized ineffective and total in addition to the base station antennas placed on the roof of the buildings. Electromagnetic field measurements were considered at 900/1800/2011 MHz frequencies.

Measuring techniques used in the study were based on recommendations specified in standards. Measurements were performed at the far field of the base station antennas. According to several guidelines, the exposure to radiofrequency electromagnetic fields is quantified in terms of measured electric field $(\mathrm{V} / \mathrm{m})$ and estimated power density $\left(\mathrm{W} / \mathrm{m}^{2}\right)$ that are the main physical parameters which have been assessed in this study.

All measurements were performed between 11:00 and 16:30 via a field meter placed on a tripod. Electric field measurements at each selected points were performed for different heights from the floor as $1 \mathrm{~m}, 1.5 \mathrm{~m}$ and $1.7 \mathrm{~m}$ for 6 minutes durations. All measurements were repeated at different hours of measurement period and a difference of $25-30 \%$ was noticed at some measurement results. Due to these differences, the highest field strength value was recorded as the measurement value of selected point. Distance between measurement points and base station antennas varied from $15 \mathrm{~m}$ to $40 \mathrm{~m}$. The diversity of distances resulted from physical conditions of measurement points. Vertical difference between measurement point and base station antenna was measured from 0 to $25 \mathrm{~m}$ and horizontal difference was from 12 to $35 \mathrm{~m}$. All distances were measured with Leica Disto D8 laser meter (0.2-200 $\mathrm{m}$ range).

The study was repeated in 2011 and 2012. In the second and third years of program, a great attention was paid for doing measurements at the same points and conditions of previous years (time period, weekday, weather condition). New-built settlements, ascending number of base stations, base stations that undergo revisions (direction or tilt change, replaced antennas) caused an increase at the number of measurements by years. A few base stations removed completely or moved to another places. So the change of the electromagnetic environment was investigated at the same locations and conditions over the previous year.

During measurements, it is aimed to prevent measurements from the effects of the operator and suppress the uncertainty of measurements by using the same measurement method, same measurement setup and performing the measurements at same conditions. But many other factors affect the measurements like intensity of communication traffic, weather, physical conditions or device and probe based uncertainties. Uncertainties of probes and devices, used in this study, can be determined from the calibration certificate documents of measurement devices and listed in Table 4.

Table 4. Uncertainties of E-field measurement devices calibration

\begin{tabular}{cccc}
\hline \multicolumn{2}{c}{ NBM550 EF Probe } & \multicolumn{2}{c}{ SRM 3006 E Probe } \\
\hline $\begin{array}{c}\text { Frequency } \\
(\mathrm{MHz})\end{array}$ & $\begin{array}{c}\text { Uncertainty } \\
(\mathrm{dB})\end{array}$ & $\begin{array}{c}\text { Frequency } \\
(\mathrm{MHz})\end{array}$ & $\begin{array}{c}\text { Uncertainty } \\
(\mathrm{dB})\end{array}$ \\
\hline $0.1-100$ & 0.5 & $26-300$ & 1 \\
$200-300$ & 0.8 & $433-1600$ & 1.5 \\
$500-1000$ & 1.5 & $1900-3000$ & 1 \\
$1800-6000$ & 0.6 & - & - \\
\hline
\end{tabular}

Measurements were also repeated in same conditions to confirm the measurement results and to overcome the effect of uncertainties like communication traffic, weather etc. Some different results were determined in terms of the overall effect of the uncertainty of measurement as (25-30)\% on measurement results and the highest results were taken into account as measurement results.

At the end of the project, electromagnetic environment at homes and streets near the base stations in Nilüfer district was analyzed and change of electromagnetic environment was observed during three years. The electromagnetic fields radiated from transmitters of base stations measured between frequencies from $700 \mathrm{MHz}$ to $3 \mathrm{GHz}$. $900 \mathrm{MHz}, 1800 \mathrm{MHz}$ and $2100 \mathrm{MHz}$ GSM frequencies were especially focused on. Frequency level measurement was realized with spectrum analyzer when needed. The distribution of the measured values, analysis of statistical situation and review in terms of national and international limits were given with the graphs.

\section{Results}

In this study, the electromagnetic field measurement results obtained between 2010 and 2012 in Bursa/Nilüfer are presented. 86, 98 and 228 measurements were performed in 2010, 2011 and 2012, respectively. Electromagnetic exposure was undertaken at indoor and outdoor locations at vicinity of the base station antennas over three years in the city. An assessment was made by comparing the measured electric field levels with guidelines on limiting people exposure published by ICNIRP and other regulations which have been applying exposure of the precaution limits. The measurement values for all points and levels according to the limits are given graphically. In addition, the numerical distributions of electric field measurements are given in graphs. Also, the changing level 
of the results according to years are presented in the study. The total electromagnetic exposure with GSM band frequencies quotients due to all GSM signals frequencies with $900 / 1800 / 2100 \mathrm{MHz}$ measured ranged from $0.3 \%$ to $27 \%$ of the ICNIRP reference levels for exposure of the general public(for $900 \mathrm{MHz}$ ). The results of this work may be useful to gain information on public exposure to total electromagnetic fields from GSM antennas. Also uptrending rate of the electromagnetic power density determined in the environment of sensitive areas with respect to year by year.

Table 5. Electric field measurement results - maximum value and ratios by reference levels

\begin{tabular}{cccc}
\hline Year & $\begin{array}{c}\text { Maximum } \\
\text { Electric Field } \\
\text { Strength } \\
(\mathrm{V} / \mathrm{m})\end{array}$ & $\begin{array}{c}\text { Ratio by } \\
\text { ICNIRP } \\
\text { Reference Level } \\
(\%)\end{array}$ & $\begin{array}{c}\text { Ratio by BTK } \\
\text { Reference Level } \\
\text { (for Single } \\
\text { GSM) (\%) }\end{array}$ \\
\hline 2010 & 4.7 & 12 & 46 \\
2011 & 11 & 27 & 108 \\
2012 & 10 & 24 & 98 \\
\hline
\end{tabular}

Table 6. Electric field measurement results - averaged values and ratios by reference levels

\begin{tabular}{cccc}
\hline Year & $\begin{array}{c}\text { Average } \\
\text { Electric Field } \\
\text { Strength } \\
(\mathrm{V} / \mathrm{m})\end{array}$ & $\begin{array}{c}\text { Ratio by } \\
\text { ICNIRP } \\
\text { Reference } \\
\text { Level(\%) }\end{array}$ & $\begin{array}{c}\text { Ratio by BTK } \\
\text { Reference Level } \\
\text { (for Single GSM) } \\
(\%)\end{array}$ \\
\hline 2010 & 0.91 & 2 & 9 \\
2011 & 1.38 & 3 & 13 \\
2012 & 1.54 & 4 & 15 \\
\hline
\end{tabular}

Table 7. Power density estimation - maximum values and ratios by reference levels

\begin{tabular}{cccc}
\hline Year & $\begin{array}{c}\text { Maximum } \\
\text { Power Density } \\
\text { Strength } \\
\left(\mathrm{mW} / \mathrm{m}^{2}\right)\end{array}$ & $\begin{array}{c}\text { Ratio by } \\
\text { ICNIRP } \\
\text { Reference Level } \\
(\%)\end{array}$ & $\begin{array}{c}\text { Ratio by BTK } \\
\text { Reference Level } \\
\text { (for Single } \\
\text { GSM) }(\%)\end{array}$ \\
\hline 2010 & 59.8 & 1 & 21 \\
2011 & 321 & 7 & 114 \\
2012 & 267 & 6 & 95 \\
\hline
\end{tabular}

Table 8 . Power density estimation - averaged values and ratios by reference levels

\begin{tabular}{cccc}
\hline Year & $\begin{array}{c}\text { Average } \\
\text { Power Density } \\
\text { Strength } \\
\left(\mathrm{mW} / \mathrm{m}^{2}\right)\end{array}$ & $\begin{array}{c}\text { Ratio by } \\
\text { ICNIRP } \\
\text { Reference Level } \\
(\%)\end{array}$ & $\begin{array}{c}\text { Ratio by BTK } \\
\text { Reference Level } \\
\text { (for Single } \\
\text { GSM) }(\%)\end{array}$ \\
\hline 2010 & 2.2 & 0.05 & 0.8 \\
2011 & 5.1 & 0.11 & 1.8 \\
2012 & 6.3 & 0.14 & 2.3 \\
\hline
\end{tabular}

The measurement results are presented with the graphs by years. The information contained is given both in graph titles and figure captions. The measurement values for all measurement locations are given in Figures 1, 4 and 7 for 2010, 2011 and 2012 respectively. Limit levels of Turkey (for single GSM and environment), Switzerland and Poland are also given in graphs. Numerical distributions of electric field measurements are given in Figures 2, 5 and 8 by years, respectively. The numerical distribution of all measurements performed during 3-year period is given in Figure 10. In addition, distribution of electric field measurements by distance are given in Figures 3, 6 and 9 for 2010, 2011 and 2012 respectively.

Maximum and average values of electric field measurements are given with ratios by limit values of ICNIRP and BTK at Tables 5 and 6 for 2010, 2011 and 2012, separately.

It is clear from Table 5 that maximum electric field measurement results are quite below the ICNIRP limits (max. 27\%). However, 2011 maximum value exceeds the permissible exposure limits for single GSM and also 2012 maximum value is nearly equal to the limit value. According to Table 6, average electric field values of each measurement year are below the ICNIRP reference level and BTK reference level for single GSM but there is a notable increasing trend of average electric field values by years.

Maximum and average values of power density are given with ratios by limit values of ICNIRP and BTK at Tables 7 and 8 for 2010, 2011 and 2012, respectively.

In 2010, 86 electric field measurements were performed at indoor places in homes located in far field of the GSM base station antennas and values of measurements are shown in Figure 1. All of the measurement results were below the national reference level for single GSM

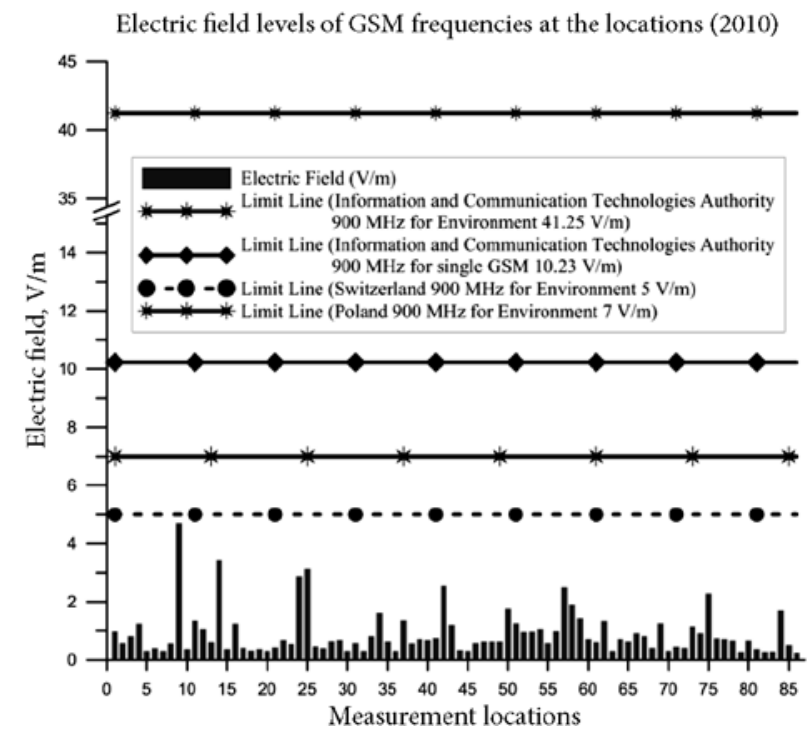

Fig. 1. Electric field measurement levels of GSM frequencies at the locations in 2010 
and ICNIRP limits. The maximum electric field strength reached $4.7 \mathrm{~V} / \mathrm{m}$ and below the reference levels. The maximum exposure was $12 \%$ of ICNIRP limits and $46 \%$ of national reference level for single GSM as shown at Table 5.

In 2010, power density values at measurement locations were in range from 0.17 to $59.8 \mathrm{~mW} / \mathrm{m}^{2}$. The

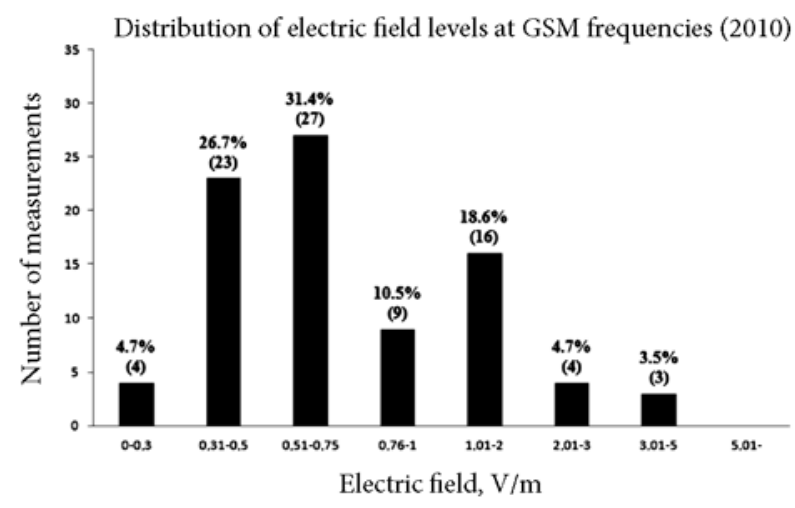

Fig. 2. Distribution of electric field levels at GSM frequencies (2010)

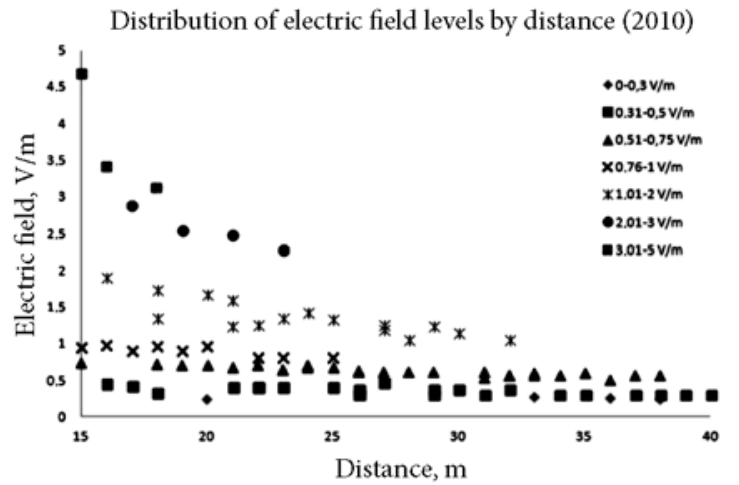

Fig. 3. Distribution of electric field levels by distance (2010)

Electric field levels of GSM frequencies at the locations (2011)

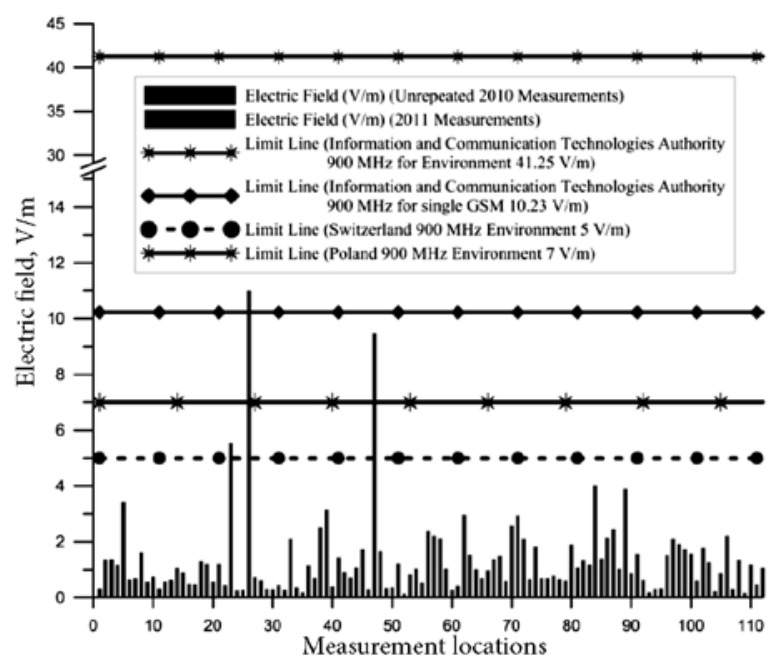

Fig. 4. Electric field measurement levels of GSM frequencies at the locations in 2011 maximum power density value is $21 \%$ of BTK single GSM reference level and also $1 \%$ of ICNIRP limit. Average power density of locations in 2010 was $2.20 \mathrm{~mW} / \mathrm{m}^{2}$.

Also, numeric distribution of 2010s electric field measurements is given in Figure 2. It is noticed that $97 \%$ ( 83 of 86 ) of the measurements are lower than $3 \mathrm{~V} / \mathrm{m}$ and $73 \%$ (63 of 86 ) are lower than $1 \mathrm{~V} / \mathrm{m}$. Due to these electric field values, average value of measurements was calculated $0.91 \mathrm{~V} / \mathrm{m}$ as given at Table 6 . Average value of the measurements was 11 times lower than national reference level for single GSM and 2\% of ICNIRP limits (for $900 \mathrm{MHz}$ ).

Distribution of electric field measurements by distance are given in Figure 3. It is clear that higher measurement results are located close to base station antennas (mostly located from $15 \mathrm{~m}$ to $25 \mathrm{~m}$ ). The highest electric field value was measured at one of the closest locations (4.7 V/m at $15 \mathrm{~m}$ distance). 23 of 86 measurement results were greater than $1 \mathrm{~V} / \mathrm{m}$. 9 of measurement results were located between $15 \mathrm{~m}$ to $20 \mathrm{~m}$ and 8 of them between $20 \mathrm{~m}$ to $25 \mathrm{~m}$. With increasing distance, measurement values were decreasing and mostly $0.5 \mathrm{~V} / \mathrm{m}$ and smaller values were measured from $25 \mathrm{~m}$ and further distances. This graphic also showed and proved the inverse relation between distance and electric field strength.

In 2011, 98 measurements were performed at indoor places at homes located in the far field of GSM base station antennas and values are shown in Figure 4.72 of 98 measurements were repeated measurements at same locations of previous year and 26 new measurement locations added to these locations. All except one of the measurement results were below the national reference level for single GSM. The maximum electric field strength was $11 \mathrm{~V} / \mathrm{m}$ and $27 \%$ of ICNIRP limits. Also, it was noticed that maximum electric field measurement value was higher than national reference level for single GSM and equal to $108 \%$ of national reference level.

In addition, different electric field values are noticed at some measurement points compared to previous year during analyzing the repeated measurements. 34 of 72 measurement values increased and 12 decreased. Measurement results in 26 locations were identified as equal in both years. Uncertainty of measurement devices are also taken into account during analyzing process.

Power density values ranged from 0.06 to $321 \mathrm{~mW} / \mathrm{m}^{2}$. The maximum power density value is $114 \%$ of BTK reference level for single GSM and 7\% of ICNIRP and BTK total reference level. Average power density was $5.1 \mathrm{~mW} / \mathrm{m}^{2}$.

In Figure 5, distribution of electric field levels are shown by numerical ranges of measurement results. Due to Figure $4,3 \%$ of measurement values (3 of 98 ) are higher than $5 \mathrm{~V} / \mathrm{m}$ and only $1 \%$ greater than $10 \mathrm{~V} / \mathrm{m}$. Electric field values are below $3 \mathrm{~V} / \mathrm{m}$ at $94 \%$ of measurement points (92 of 98) and below $1 \mathrm{~V} / \mathrm{m}$ at $48 \%$ (47 of 98 ).

Average value of measurements was $1.38 \mathrm{~V} / \mathrm{m}$ in 
2011. It was $13 \%$ of BTK national reference level for $900 \mathrm{MHz}$ and 30 times smaller than ICNIRP reference level as shown at Table 6. Average electric field strength increased $51 \%$ against 2010 average value of measurements. According to the comparison of 2010 and 2011 measurements, it was observed that the number of measurements above $1 \mathrm{~V} / \mathrm{m}$ increased $121 \%$ and raised from 23 to 51 . Also, $100 \%$ increase was noticed at number of measurements above $3 \mathrm{~V} / \mathrm{m}$ (from 3 to 6 ).

In Figure 6, distribution of electric field measurements by distance in 2011 is given. 50\% of measurement locations are between $15 \mathrm{~m}$ to $25 \mathrm{~m}$. 30 of 51 electric field measurements greater than $1 \mathrm{~V} / \mathrm{m}$ are located between 15-25 m scale. The highest electric field value was measured at $16 \mathrm{~m}$ away from the related base station. With increasing distance, measurement values were decreasing and mostly $0.75 \mathrm{~V} / \mathrm{m}$ and smaller values were measured from $25 \mathrm{~m}$ and further distances. 23 of 30 measurement values are smaller than $1 \mathrm{~V} / \mathrm{m}$ between $30-40 \mathrm{~m}$ scale.

Electric field measurement levels of 2012 are shown in Figure 7. Differ from 2010 and 2011, number of measurements increased and 228 measurements were performed. 90 of 228 measurements were repeated measurements at same locations of previous year and 138 new measurement locations added to these locations. The main reason of increasing number of measurements is new base stations antennas mounted on the street lighting poles at a height of 4-5 meters located through the street. Also, new settlements and base stations that undergo revisions are the other reasons of increase.

The maximum electric field strength was measured as $10 \mathrm{~V} / \mathrm{m}$ and was equal to $98 \%$ of national reference level for single GSM. Also, it was four times lower than ICNIRP limits and the measurement location was previous year's highest value measured point.

90 measurements performed in 2011 were repeated in 2012. Compared to 2011 measurement values, 27 of 90 measurement values increased and 7 measurement values decreased. Measurement results at 56 locations were identified as equal in 2011 and 2012.

In 2012, Power density values ranged from 0.08 to $267 \mathrm{~mW} / \mathrm{m}^{2}$. The maximum power density is $95 \%$ of BTK reference level for single GSM and $6 \%$ of ICNIRP and BTK total reference level. Average power density was increased to $6.3 \mathrm{~mW} / \mathrm{m}^{2}$.

Distribution of measurement values by numerical ranges are given in Figure $8.3 \%$ of all measurement values ( 7 of 228 ) are greater than $5 \mathrm{~V} / \mathrm{m}$. It is noticed $51 \%$ of measurements (117 of 228) are below $1 \mathrm{~V} / \mathrm{m}$ and $90 \%$ of measurements (205 of 228) are less than $3 \mathrm{~V} / \mathrm{m}$.

In 2012, average value of measurements was $1.54 \mathrm{~V} / \mathrm{m}$ and continued increasing. It was $4 \%$ of ICNIRP limits and $15 \%$ of national reference value for single GSM as shown at Table 6. Average electric field strength increased 12\% against 2011 average value of measurements and 69\% against 2010. According to the comparison of 2011 and 2012 measurements, it was observed that the number of measurements higher than $1 \mathrm{~V} / \mathrm{m}$ increased $217 \%$ and raised from 51 to 111 . Also, number of measurements higher than $3 \mathrm{~V} / \mathrm{m}$ nearly quadrupled and

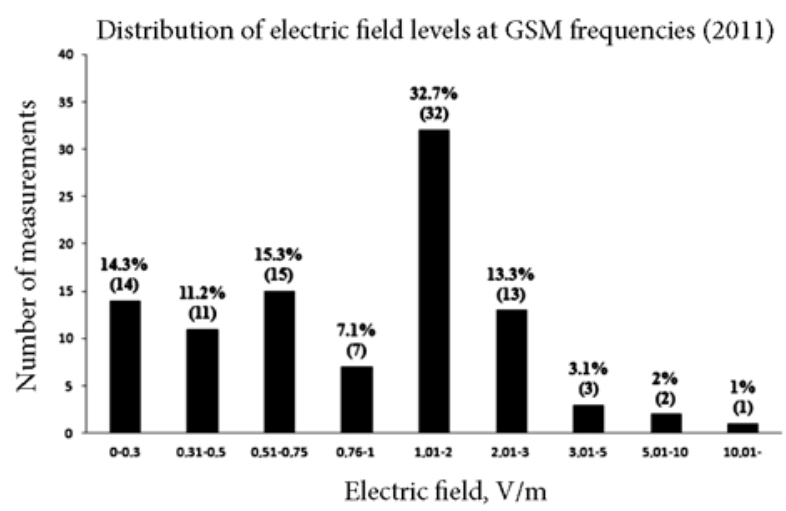

Fig. 5. Distribution of electric field levels at GSM frequencies (2011)

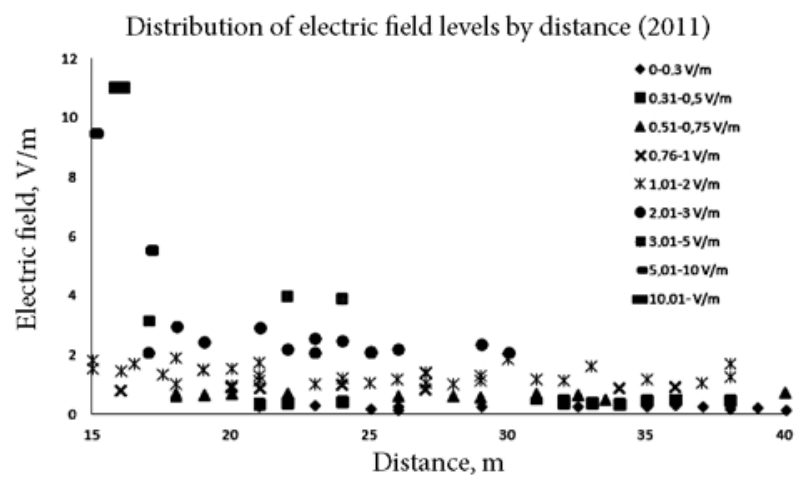

Fig. 6. Distribution of electric field levels by distance (2011)

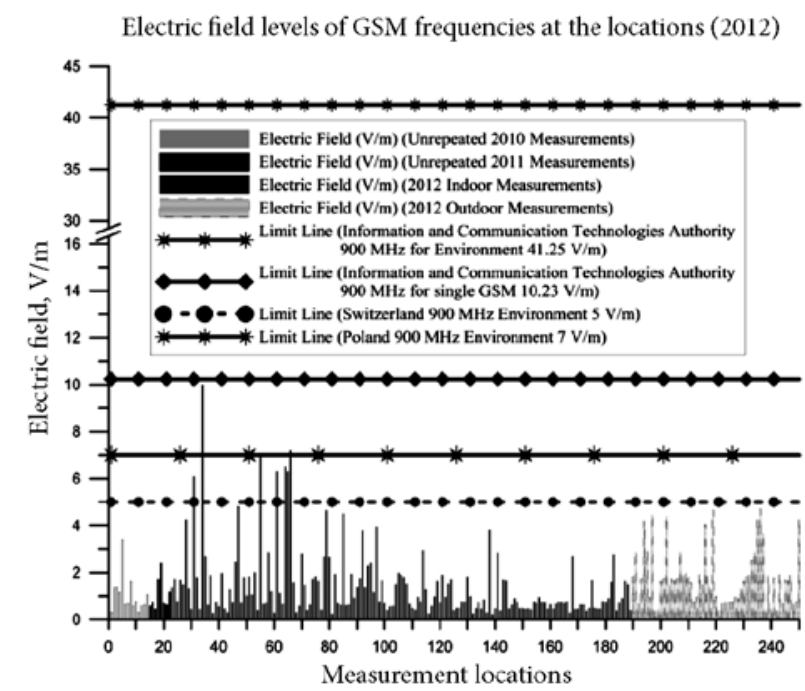

Fig. 7. Electric field measurement levels of GSM frequencies at the locations in 2012 


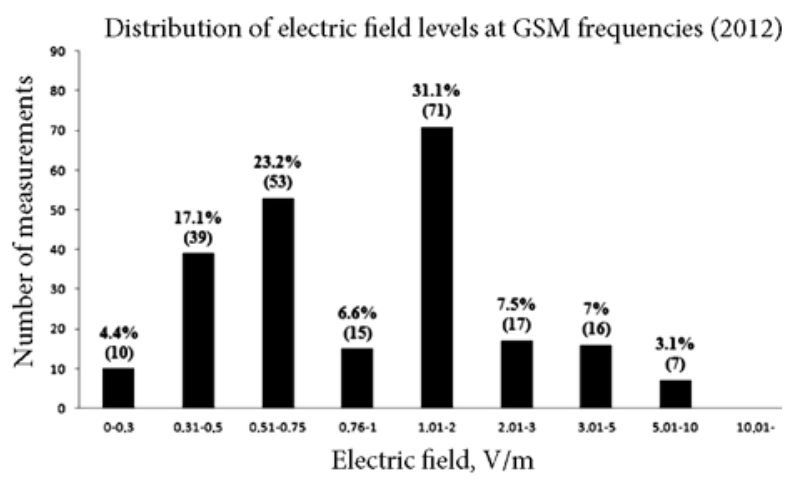

Fig. 8. Distribution of electric field levels at GSM frequencies (2012)

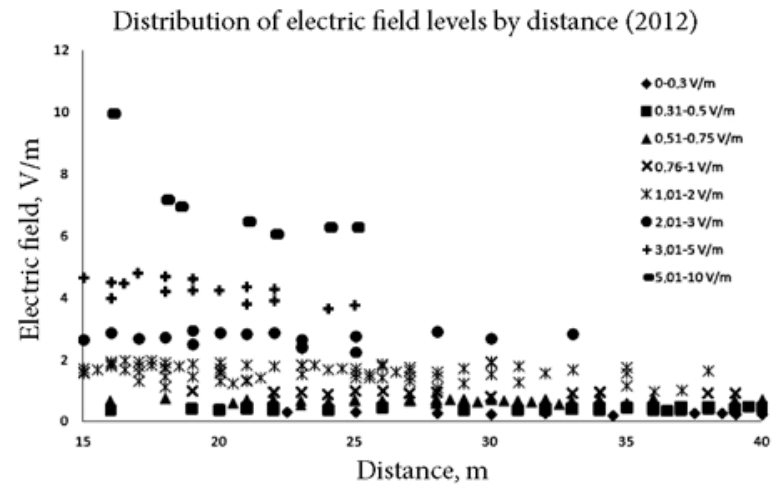

Fig. 9. Distribution of electric field levels by distance (2012)

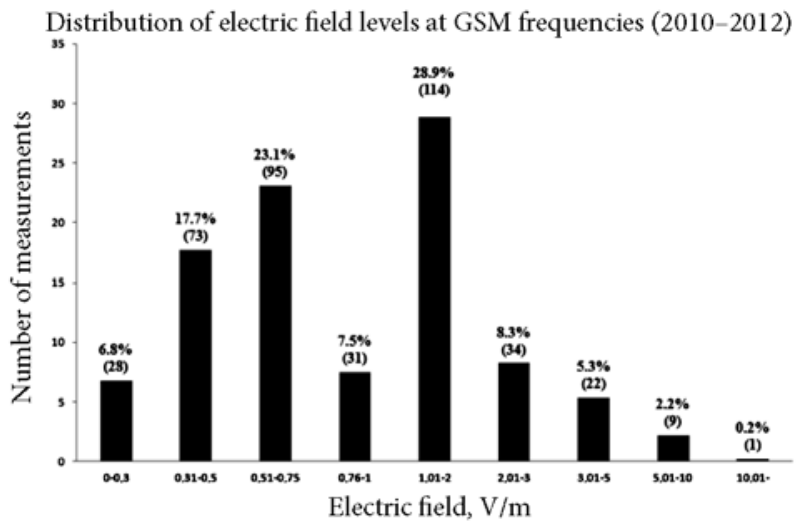

Fig. 10. Distribution of electric field levels at GSM frequencies (2010-2012)

raised to 23 from 6 . The main reason of the increment at number of measurements was 61 base station mounted on street lightning poles.

Distribution of electric field measurements by distance in 2012 are given in Figure 9. The highest measurement values are clearly close to base station antennas and located between $15 \mathrm{~m}$ to $25 \mathrm{~m}$. All of the measurement values greater than $3 \mathrm{~V} / \mathrm{m}$ are located closer than or equal to $25 \mathrm{~m}$. 111 measurement results were greater than $1 \mathrm{~V} / \mathrm{m}$. 48 of measurement results were located between 15-20 m and 32 of between 20-25 m. With increasing distance, measurement values were decreasing and mostly $0.75 \mathrm{~V} / \mathrm{m}$ and smaller values were measured from $25 \mathrm{~m}$ and further distances. Some values are greater than $0.75 \mathrm{~V} / \mathrm{m}$ located in this scale.

In 2012, number of measurement locations were increased due to newly installed base stations mounted on street lightning poles. These base antennas mounted at a height of 8-10 $\mathrm{m}$ from the ground and distances between base antenna and measurement locations are generally 15 to $25 \mathrm{~m}$. Due to this situation, differ from Figures 3 and 6 , number of measurements between 15 to $25 \mathrm{~m}$ are increased as shown in Figure 9. Compared to Figures 3, 6 and 9, the increase of measurement results between 1-2 V/m scale mostly depended on these new installations.

With this detailed and long-term work, large numbers of measurements were realized. Many significant results have been obtained with analyzing and evaluating the result of measurements. First of all, it can be easily seen that the limit values are much greater than the real environment results. All except one of the electric field measurement values are lower than single GSM base station limit value $(10.23 \mathrm{~V} / \mathrm{m}$ for $900 \mathrm{MHz}$ frequency) and all of measurement results are lower than ICNIRP and BTK total GSM exposure reference levels. $97 \%$ of measurement values are below $5 \mathrm{~V} / \mathrm{m}$ and $84 \%$ are below $2 \mathrm{~V} / \mathrm{m}$ as shown in Figure 10. In this context, total environment limit values $(41-61 \mathrm{~V} / \mathrm{m})$ are pointed out an extremely high level and current limit values should be revised and lowered. If electromagnetic fields in sensitive places is desired to be constituted homogeneous distribution, the regulation limits can be lower to $5 \mathrm{~V} / \mathrm{m}$ from $41-61 \mathrm{~V} / \mathrm{m}$.

Countries have used different limit values for electric field strength. Some countries such as Switzerland, Italy and Poland have applied lower limits than ICNIRP levels in sensitive areas. Also countries like France, Germany, Spain, Sweden, Cyprus, Finland, Austria, Ireland and UK have set ICNIRP limits $(41-61 \mathrm{~V} / \mathrm{m})$ for electric field exposure (Stam 2011).

During 3-year period, it was observed that all of the measurement results higher than $3 \mathrm{~V} / \mathrm{m}$ were located between 15 to $25 \mathrm{~m}$ away from base station antennas. 20 of 32 measurement results were 15 to $20 \mathrm{~m}$ and the rest were 20 to $25 \mathrm{~m}$. This situation mostly resulted from selection of emission points of the base stations close and at same height to the homes or crowded outdoor places. The combination of this situation with high electromagnetic exposure limits applied in Turkey can be caused high measurement results. Therefore, placement of base station antennas was also an important factor to be considered during the planning phase.

412 measurements were performed at 250 locations (189 indoor and 61 outdoor) from stations 2010 to 2012. 
64 of 250 locations investigated over 3 years (2010 to 2012). Measurement results at 12 locations were identified as equal during measurement period and measurement results changed at 52 locations. Electromagnetic exposure level at 19 of 64 locations increased over 3 years. Also, at 3 of 64 locations, electromagnetic exposure level decreased continuously during measurement period.

Average measurement results show that the electromagnetic exposure at residential areas increased continuously during 3-year period as shown at Tables 6 and 8 . Due to increasing population and demand, new base stations installed and revisions made at some base stations (change of tilt or/and direction, replace base antennas with powerful antennas, relocated or removed base stations). Also, new-built settlements around base stations and base station mounted on street lightning poles caused the increment of electromagnetic exposure at indoor and outdoor places at the vicinity of base stations.

Average electric field values increased from $0.91 \mathrm{~V} / \mathrm{m}$ to $1.54 \mathrm{~V} / \mathrm{m}$. $69 \%$ increase determined from 2010 to 2012. The highest average value was $1.54 \mathrm{~V} / \mathrm{m}$ in 2012 and 7 times lower than BTK single GSM reference level. Also, power density values showed the same characteristics and increased from $2.2 \mathrm{~mW} / \mathrm{m}^{2}$ to $6.3 \mathrm{~mW} / \mathrm{m}^{2}$. About $200 \%$ increase noticed from 2010 to 2012 at average power density values. The maximum average value that obtained in 2012 was $2.3 \%$ of BTK reference level for single GSM (900 MHz).

Average exposure levels obtained from the study are quite below compared to the limits. But increase of average values during 3-year period is remarkable and evolution of electromagnetic exposure must be monitored carefully at coming years.

\section{Conclusions}

In this study, electromagnetic exposure levels were determined especially for the indoor and outdoor environments near base station antennas at Bursa/Nilüfer district via 412 electromagnetic field measurements from 2010 to 2012. Bursa/Nilüfer district is a growing city with its 300000 population. It can be stated that there are variations between measurements values by years. The main reason of variations are new established or removed base stations, revisions of local old base stations and new built settlements in the city.

It was understood from the repeated measurements at same points that evolving GSM base antennas, application of ICNIRP limits at the highest levels and increasing number of the base stations based on the rapid progress at communication technology caused electromagnetic exposure at indoor places ranging from $0.3 \mathrm{~V} / \mathrm{m}$ to $11 \mathrm{~V} / \mathrm{m}$ for $15 \mathrm{~m}$ to $40 \mathrm{~m}$ distances between measurement points and base station antennas in Nilüfer/Bursa.
It is noticed that none of the measurement values exceeded the ICNIRP reference level and only one value is greater than national BTK reference level for single GSM at $900 \mathrm{MHz}(11 \mathrm{~V} / \mathrm{m}$ in 2011).

According to measurement results, 97\%, 92\% and $84 \%$ of measurement values are lower than $5 \mathrm{~V} / \mathrm{m}, 3 \mathrm{~V} / \mathrm{m}$ and $2 \mathrm{~V} / \mathrm{m}$, respectively. $5 \mathrm{~V} / \mathrm{m}$ or greater values were measured at 10 of 412 measurements ( 3 in 2011 and 7 in 2012) and 3 locations were same places in 2011 and 2012.

32 of 412 measurement results were greater than $3 \mathrm{~V} / \mathrm{m}$. 20 of 32 measurement results were located between 15 to $20 \mathrm{~m}$ and the rest were 20 to $25 \mathrm{~m}$. Selection and placement of base station antennas is also an important factor to be considered during the planning phase.

Average electromagnetic exposure levels in sensitive places has risen up by 3-year period. In 2010, average electric field value was $0.91 \mathrm{~V} / \mathrm{m}$ and increased to $1.38 \mathrm{~V} / \mathrm{m}$ and $1.54 \mathrm{~V} / \mathrm{m}$ in 2011 and 2012, respectively. During 3 -year period, an increase of $69 \%$ was determined and this instant increase has to be monitored in coming years and some precautions taken into account. This increase can contain data's that will be basis for long term studies, such as 5-10 years.

According to measurement values and numerical distribution, possibility of controlling electric field levels below $5 \mathrm{~V} / \mathrm{m}$ can be questionable to minimize the electromagnetic exposure radiated from GSM antennas in living areas. Also, this study shows that it may be reasonable to apply precaution limit values used in Switzerland, Italy and Poland.

Electromagnetic power density limits of ICNIRP were not exceed indoor places of the residences during measurement period.

Average electromagnetic power density has increased from $2.20 \mathrm{~mW} / \mathrm{m}^{2}$ to $6.29 \mathrm{~mW} / \mathrm{m}^{2}$ during 3-year period.

It is important to note that present threshold limits described by the ICNIRP are considered to be rather too generous and hence there is a need to review the limits. Some countries like Switzerland, Poland and Italy use lowered reference levels. These applications prove that lower reference levels can be applied successfully. To control the electromagnetic exposure in Turkey restricting ICNIRP reference limits as given European countries can be recommended as more accurate method.

This research shows an increasing trend emerging in the electromagnetic field by years of exposure values and it can be reference to discuss possible situations will be caused by the rapid development of communication technology that concern every country on the world. As a result, it is clear that keeping the electromagnetic exposure limits as low as possible is the most efficient and correct application to reduce and control the continuous involuntary electromagnetic field exposure.

Safety concern regarding the biological effects of electromagnetic radiation including low level of exposure 
have been raised. Long time exposure to radiation of GSM transmission antennas in rooms near the base station antennas is a fact to be considered. And the potential biological effects of exposure to these sources are to take into account.

\section{Acknowledgments}

The authors would like to thank to Bursa/Nilüfer municipality for their support and opportunities provided to do this work.

\section{References}

Alanko, T.; Hietanen, M.; von Nandelstadh, P. 2008. Occupational exposure to RF fields from base station antennas on rooftops, Annals of Telecommunications 63: 125-132. http://dx.doi.org/10.1007/s12243-007-0001-6

Baltrenas, P.; Buckus, R.; Vasarevicius, S. 2012. Research and evaluation of the intensity parameters of electromagnetic fields produced by mobile communication antennas, Journal of Environmental Engineering and Landscape Management 20(4): 273-284.

http://dx.doi.org/10.3846/16486897.2012.738680

Bernardi, P.; Cavagnaro, M.; Pisa, S.; Piuzzi, E. 2000. Human exposure to radio base-station antennas in urban environment, IEEE Transactions on Microwave Theory and Techniques 48(11): 1996-2001. http://dx.doi.org/10.1109/22.884188

Chen, H. Y.; Su, T. Y.; Chuang, C. Y. 2009. Electric fields radiated from a cellular phone base station antenna constructed on a roof-top, Electromagnetics 29(3): 235-249. http://dx.doi.org/10.1080/02726340902718468

Cooper, J.; Marx, B.; Buhl, J.; Hombach, V. 2002. Determination of safety distance limits for a human near a cellular base station antenna, adopting the IEEE standards or ICNIRP guidelines, Bioelectromagnetics 23(6): 429-443.

http://dx.doi.org/10.1002/bem.10037

Çerezci, O.; Şeker, S. 2010. Determining of electromagnetic pollution in Bursa Nilufer district and recommending a sample model to decrease exposure levels, in National Conference on Electrical, Electronics and Computer Engineering ELECO' 2010 [online], 2-5 December 2010, 1-5 [cited 10 February 2013]. Available from Internet: http://ieeexplore.ieee.org/ xpls/abs_all.jsp?arnumber $=5698224$

EN 50413: 2008. Basic Standard on Measurement and Calculation Procedures for Human Exposure to Electric, Magnetic and Electromagnetic Fields $(0 \mathrm{~Hz}-300 \mathrm{GHz})$. European Committee for Electrotechnical Standardization (CENELEC). 59 p.

Gosselin, M. C.; Christ, A.; Kühn, S.; Kuster, N. 2009. Dependence of the occupational exposure to mobile phone base stations on the properties of the antenna and the human body, IEEE Transactions on Electromagnetic Compatibility 51(2): 227-235.

http://dx.doi.org/10.1109/TEMC.2009.2013717

Higashiyama, J.; Tarusawa, Y. 2011. RF exposure compliance assessment for radio base station with built-in antenna, in Proceedings of $10^{\text {th }}$ International Symposium of Electromagnetic Compatibility EMC Europe 2011 [online], 26-30 September 2011, York, UK, 90-93 [cited 12 March 2013]. Available from Internet: http://ieeexplore.ieee.org/xpl/articleDetails. jsp?tp=\&arnumber $=6078580$

International Commission on Non-Ionizing Radiation Protection (ICNIRP). 1998. ICNIRP guidelines for limiting exposure to time-varying electric, magnetic and electromagnetic fields (up to $300 \mathrm{GHz}$ ), Health Physics [online] 74(4): 494522 [cited 12 March 2013]. Available from Internet: http:// www.icnirp.org/cms/upload/publications/ICNIRPemfgdl.pdf

Information and Communication Technologies Authority (BTK). 2011. Regulation on Electromagnetic Exposure the limit values of the Electromagnetic Field force from the fixed telecommunication devices operating within the frequency range of $10 \mathrm{kHz}-60 \mathrm{GHz} .7$ p. [online], [cited 12 March 2013]. Available from Internet: http://tk.gov.tr/mevzuat/yonetmelikler/ dosyalar/ehc.pdf

Joseph, W.; Martens, L. 2005. Comparison of safety distances based on the electromagnetic field and based on the SAR for occupational exposure of a $900-\mathrm{MHz}$ base station antenna, IEEE Transactions on Electromagnetic Compatibility 47(4): 977-985. http://dx.doi.org/ 10.1109/temc.2005.854100

Karpowicz, J.; Hietanen, M.; Gryz, K. 2006. EU directive, ICNIRP guidelines and Polish legislation on electromagnetic fields, International Journal of Occupational Safety and Ergonomics [online] 12: 125-136 [cited 12 March 2013]. Available from Internet: http://www.ciop.pl/17469

Neskovic, N.; Koprivica, M.; Neskovic, A.; Paunovic, G. 2011. Improving the efficiency of measurement procedures for assessing human exposure in the vicinity of mobile phone (GSM/ DCS/UMTS) base stations, Radiation Protection Dosimetry 149(3): 238-244. http://dx.doi.org/10.1093/rpd/ncr248

The Federal Office for the Environment (FOEN). 1999. Ordinance relating to Protection from Non Ionizing Radiation (ONIR). 20 p. [online], [cited 12 March 2013]. Available from Internet: http://www.bafu.admin.ch/elektrosmog/01079/ index.html?lang=en

Poljak, D.; Kovac, N. 2004. The boundary element electromagnetic-thermal analysis of human exposure to base station antennas radiation, Engineering Analysis with Boundary Elements 28(7):763-770.

http://dx.doi.org/10.1016/j.enganabound.2004.02.004

Singh, R. K. 2012. Assessment of electromagnetic radiation from base station antennas, Indian Journal of Radio \& Space Physics [online] 41: 557-565 [cited 28 February 2013]. Available from Internet: http://nopr.niscair.res.in

Stam, R. 2011. Comparison of international policies on electromagnetic fields (power frequency and radiofrequency fields) [online]. Netherlands National Institute for Public Health and the Environment. 13 p. [cited 15 February 2014]. Available from Internet: http://www.rivm.nl

Viel, J. T.; Clerc, S.; Barrera, C.; Rymzhanova, R.; Moissonnier, M.; Hours, M.; Cardis, E. 2009. Residential exposure to radiofrequency fields from mobile phone base stations and broadcast transmitters: a population-based survey with personal meter, Occupational \& Environmental Medicine 66: 550-556.

Wu, T.; Shao, Q.; Yang, L.; Qi, D.; Lin, J.; Lin, X.; Yu, Z. 2012. A large-scale measurement of electromagnetic fields near GSM base stations in Guangxi, China for risk communication, $R a$ diation Protection Dosimetry 155(1): 25-31. http://dx.doi.org/10.1093/rpd/ncs309 
Osman ÇEREZCİ. Dr, Prof. (since 1999), Department of Electric-Electronic Engineering, Sakarya University. Doctor of Science (Electronic Engineering), Uludag University, 1985. First degree in Physics, Istanbul University, 1976. Employment: Professor (1999), Associate Professor (1994), Assistant Professor (1986), Sakarya University Electric-Electronic Engineering Department. Publications: author of 6 books, over 70 research papers. Research interests: biological effects of electromagnetic fields, electromagnetic compatibility and electromagnetic wave propagation.

Baha KANBEROĞLU. Master, PhD student (since 2005) and Research Assistant (since 2002), Department of ElectricElectronic Engineering, Sakarya University. Master of Science (Electronic Engineering), Sakarya University, 2005. First degree in Electric-Electronic Engineering, Sakarya University, 2002. Publications: author of 14 research papers. Research interests: electromagnetic fields and theory, electromagnetic radiation, antenna theory.

Şuayb Çağrı YENER. Dr, Research Assistant (since 2004), Department of Electric-Electronic Engineering, Sakarya University. Doctor of Science (Electronics Engineering), Department of Electronics and Communication Engineering, Istanbul Technical University, 2014. Master of Science (Electronics and Communication Engineering), Istanbul Technical University, 2007. First degree in Electrical-Electronics Engineering, Sakarya University, 2004. Publications: author of 25 research papers and proceedings. Research interests: CMOS analog circuits, memristor based circuits, electromagnetic compatibility, microwave and antenna technique. 